\title{
Creep of particle and short fibre reinforced polyurethane rubber
}

\author{
Yi Cui ${ }^{1} \cdot$ Trevor William Clyne $^{1}\left[{ }_{0}\right.$
}

Received: 8 June 2021 / Accepted: 27 October 2021 / Published online: 1 December 2021

(C) The Author(s) 2021

\begin{abstract}
Tensile stress-strain testing and creep testing have been carried out on a polyurethane rubber, at three temperatures, with and without either particulate or short fibre alumina reinforcement. A previous paper reported concerning composites with particulate reinforcement and the present work is focused on the effect of the fibres. The samples were made via a blending and extrusion process that produced a certain degree of fibre alignment (along the direction of loading). Prior milling procedures were used to produce fibres with two different ranges of aspect ratio (with averages about 10 and 16). When expressed as true stress-strain relationships, all materials exhibit approximately linear responses. The dependence of stiffness on the volume fraction and aspect ratio of the reinforcement was found to conform well to the Eshelby model predictions. Moreover, the creep behaviour of all of the materials can be captured well by a Miller-Norton formulation, using the average matrix stress predicted by the Eshelby model. A striking conclusion is that it is both predicted and observed that short fibres are much more effective in reducing the creep rate than is the case with particles.
\end{abstract}

Keywords Rubber · Creep · Short fibres · Eshelby · Miller-Norton · Composite · Load transfer

\section{Introduction}

There has long been interest in creep of rubbers (Plazek 1966; Ngo and Valdes 2007; Oman and Nagode 2014; Sagar et al. 2019), partly because rubbers or rubberized materials are commonly used in applications such as seals, damping systems etc, in which they are subjected to prolonged loads at (relatively) high temperatures (Derham 1973; Derham and Thomas 1977; Lee and Rivin 1996; Luo 2016). Furthermore, while some studies have focused on pure rubbers, much industrial usage relates to filled rubbers, so there is also interest (Ngo and Valdes 2007; Oman and Nagode 2014; Chen and Cheng 1997; Daver et al. 2016) in (creep of) composite materials based on rubber matrices. In most cases, the filler material is particulate, with relatively little work (Lee and Liu 1994; Aboudi 2004; Bocchieri and Schapery 2004) having been done on rubbers containing fibrous reinforcement.

T.W. Clyne

twc10@cam.ac.uk

1 Department of Materials Science \& Metallurgy, Cambridge University, 27 Charles Babbage Road, Cambridge CB3 OFS, UK 
The mechanical behaviour of rubbers is complicated by the large elastic strains that they exhibit. Differences between true and nominal values of both stress and strain are sometimes ignored, but this has the potential to cause considerable confusion when analyzing the behaviour of rubbers, since these diverge substantially at high strain levels. Furthermore, as with many creep situations, it is often important to take account of both primary and secondary creep regimes. Information about the basic mechanisms of creep in rubbers is rather limited. It might be expected that creep resistance would be greater for rubbers with a higher cross-link density and indeed there are a few reports (Banerjee and Bhowmick 2017; Ramachandran et al. 2017) specifically confirming this. There is also a tendency for creep resistance to be reduced as the temperature is raised, although this is sometimes complicated by the associated increase in stiffness (dominated by the entropy effect).

The effects of (inert, hard) fillers might be expected to be somewhat simpler to predict than the basic response of the rubber, with a progressive increase in creep resistance expected as the filler content is raised. On one hand, an effect of this type is expected as a result of load transfer (from the matrix to the stiff reinforcement), making the average stress level in the matrix lower and hence reducing the creep rate. On the other hand, the matrix stress state is commonly very inhomogeneous, with some regions being subjected to higher local stress than that being applied (Clyne and Hull 2019). In fact, there have been very few systematic studies of the effect of filler content on the creep of rubber-based composites, with either particulate or fibrous reinforcement.

The work presented here concerns the creep of a particular (polyurethane) rubber, with and without reinforcement, as a function of applied stress and temperature. An earlier paper (Cui et al. 2020) reported on the effect of particulate reinforcement, which significantly reduces creep rates. However, this effect is not dramatic, which is attributed to the relatively low degree of load transfer from matrix to particles. Short fibres, aligned along the loading direction, are expected to have a stronger effect and the current paper is focused on this issue.

\section{Experimental procedures}

\subsection{Material and sample preparation}

Fibrous composites were produced using "Saffil" alumina fibres, supplied by Saffil Ltd (Widnes) loose in large bags. Their diameter is ca $3 \mu \mathrm{m}$. Detailed information about this type of fibre, which has been extensively used as reinforcement for MMCs, is available in Clyne et al. (1985), Clyne and Mason (1987), Friend (1987), Das et al. (1988). In the as-received form, these fibres have lengths in the millimetre range, with the associated high aspect ratios creating extensive tangles-making the product an aggregated mass or "blanket". In order to convert this material into a form suitable for production of (aligned) composite material containing dispersed short fibres, a ball milling operation was carried out, using a DECO All-Direction Planetary Ball Mill. Four layers of fibre mats ( $5 \mathrm{~g}$ in weight each) were placed in a 1.5-L alumina chamber, interspersed with five layers of alumina balls (40 pieces each), of diameter $10.75 \mathrm{~mm}$. The rotation speed of the container was $300 \mathrm{rpm}$, with the direction of rotation reversed once per minute.

This ball milling operation disentangled the fibres and reduced the average fibre lengths to the range of a few tens of microns. The milling time was used as a variable in order to produce fibres with two different average aspect ratios. It was found that periods of $3 \mathrm{~min}$ and $7 \mathrm{~min}$ were suitable for this purpose. Figure 1 shows SEM micrographs of the resultant products. It can be seen that, in both cases, the product contained a range of fibre aspect ratios, but there is clearly a difference between the two, with the shorter period leading 

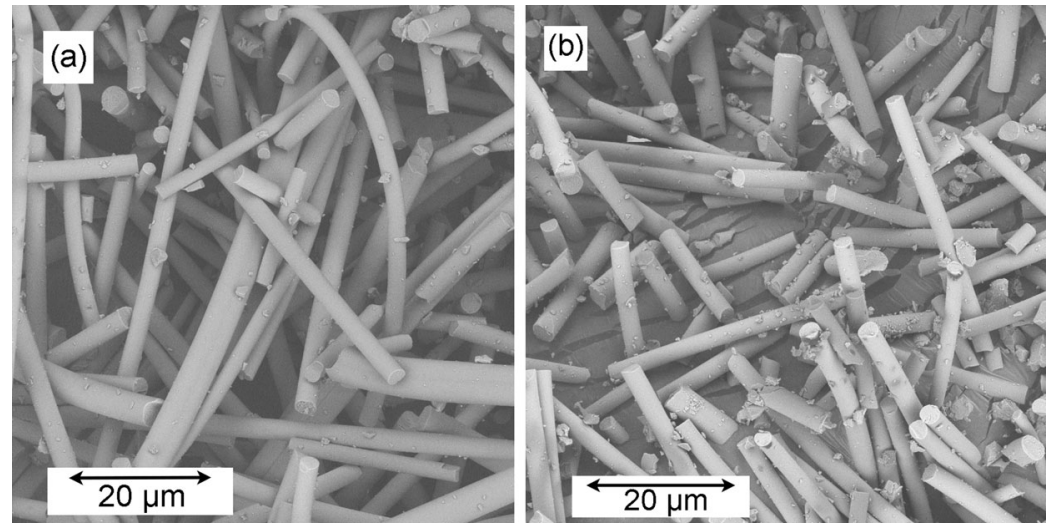

Fig. 1 SEM images of alumina fibres after milling periods of: (a) $3 \mathrm{~min}$ and (b) $7 \mathrm{~min}$

a value apparently of the order of 10-30 and the longer period to something like 5-15. However, issues concerned with sampling and possible further changes or selectivity during production of the composite are such that it is not really practicable to attempt to measure an average aspect ratio from images such as these.

Seven materials were employed in the present investigation, all based on a 2-part polyurethane rubber (Poly 74-30, supplied by WP Northcott), one part (A) being a polyurethane monomer (with $\leq 1 \%$ toluene di-isocyanate) and the other (B) being polyol and di-ethyl-toluenediamine. Details of how unfilled and particulate-reinforced composites were produced are supplied in the previous publication (Cui et al. 2020). The alumina particulate was equiaxed, with a particle size around $30 \mu \mathrm{m}$. Fibre-reinforced composites were manufactured using a similar (blending and extrusion) technique, producing cylindrical samples of $8.5-\mathrm{mm}$ diameter. However, while particulate composites were successfully manufactured with reinforcement contents of $10 \%$ and $20 \%$ (by volume), fibre contents above $10 \%$ created mixtures with too high a viscosity for extrusion. Fibre composites were therefore made with target contents of 5\% and $10 \%$ (by volume). These were produced using either the higher aspect ratio fibres (3-min milling) or those with the lower range (7-min milling).

\subsection{Microstructural characterisation}

It was shown in the previous paper (Cui et al. 2020) that the spatial distribution of the reinforcement particles was fairly uniform and that the interfacial bonding appeared to be good. For the fibrous reinforcement, there is the additional issue of fibre alignment. The extrusion procedure does tend to produce alignment of the fibres along the axis of the sample, although this alignment is naturally not perfect. An impression of this, and also of the spatial distribution, can be obtained from Fig. 2, which shows SEM micrographs of the four types of fibre composite. These show both a "cut" lateral surface and a "fracture" (transverse) surface. While neither the degree of alignment nor the spatial uniformity is perfect, the fibres appear to be fairly well-dispersed and there is certainly a degree of alignment. It can also be seen that there is some porosity. Incidentally, the fibre pull-out observed in these micrographs might be taken as indicative of poor bonding, but in fact it is likely that the bonding remained good throughout elastic and creep deformation.

In order to explore this a little further, and also to obtain information about the actual volume fractions of reinforcement, density measurements were carried out on all 7 materials. 

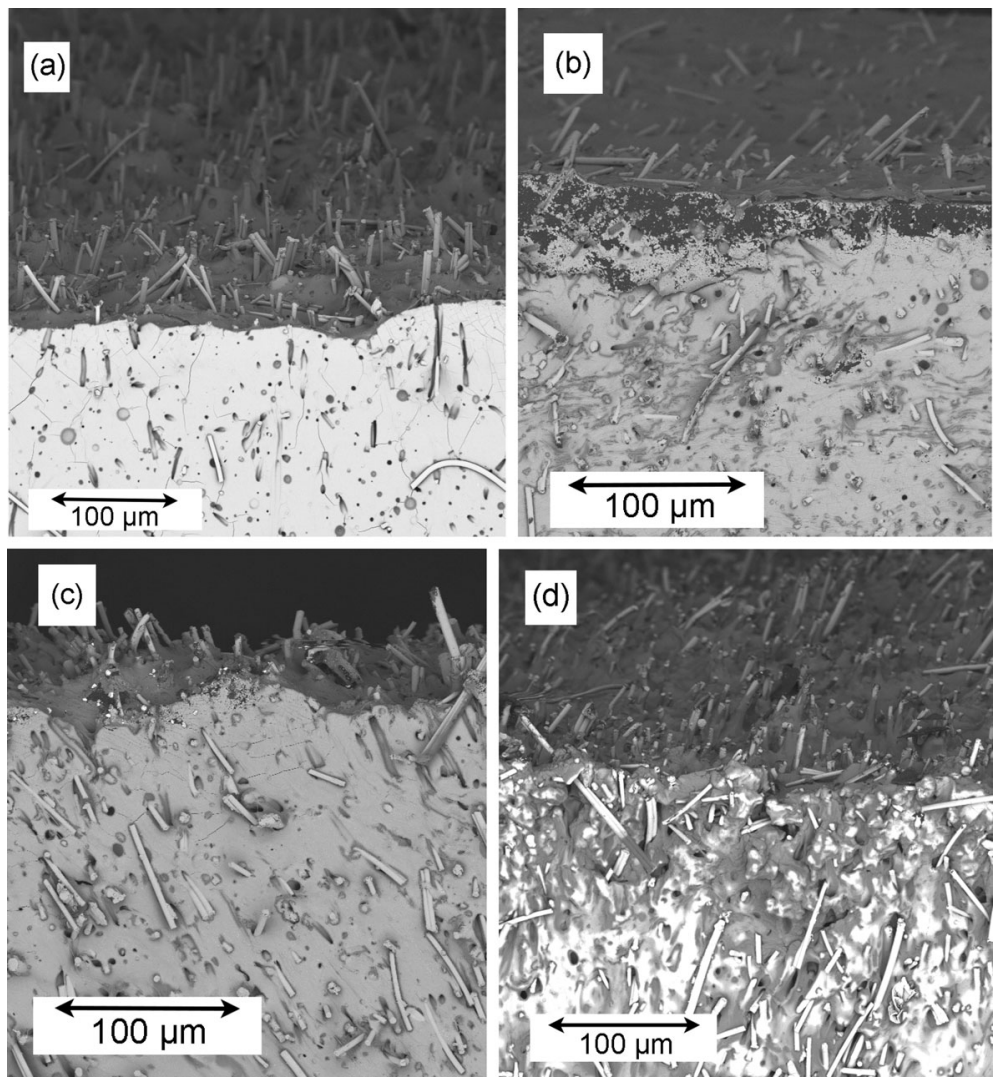

Fig. 2 SEM images of composites with the following fibre contents: (a) 5\% (3-min milling), (b) 5\% (7-min), (c) $10 \%(3 \mathrm{~min})$ and (d) $10 \%(7 \mathrm{~min})$

This was done by hydrostatic weighing, using deionized water as the immersion fluid (with a density of $0.987 \mathrm{~g} \mathrm{~cm}^{-3}$ at $20^{\circ} \mathrm{C}$ ). The outcomes are shown in Table 1 . The density value quoted by the supplier of the rubber is $1.006 \mathrm{~g} \mathrm{~cm}^{-3}$, but in fact the measured value was slightly higher than this, and so was taken as the correct fully dense value. The alumina (particulate and fibres) was taken to have a density of $3.99 \mathrm{~g} \mathrm{~cm}^{-3}$. As reported previously (Cui et al. 2020), the measured densities of the particulate composites were close to the corresponding fully dense values, suggesting porosity levels of just over $1 \%$. As might have been expected, the fibre-reinforced composites contained slightly higher porosity levels, particularly with the higher of the two fibre contents and the lower of the two aspect ratios (longer milling time). This effect should be borne in mind, although the porosity levels are all relatively low and are unlikely to have a marked effect on the mechanical characteristics. Of course, it is also possible that the actual fibre levels differed somewhat from the nominal levels, although again it seems unlikely that the errors involved are very large.

\subsection{Mechanical testing}

Two types of tests were carried out, in each case on all 7 types of material and at 3 different temperatures $\left(20^{\circ} \mathrm{C}, 45^{\circ} \mathrm{C}\right.$ and $\left.65^{\circ} \mathrm{C}\right)$. These were, firstly, conventional tensile stress-strain 
Table 1 Densitometry data for the 7 materials

\begin{tabular}{|c|c|c|c|}
\hline \multirow[t]{2}{*}{ Material } & \multicolumn{2}{|c|}{ Densities $\left(\mathrm{g} \mathrm{cm}^{-3}\right)$} & \multirow{2}{*}{$\begin{array}{l}\text { Inferred } \\
\text { porosity } \\
\text { level }(\%)\end{array}$} \\
\hline & Measured & Expected & \\
\hline Unfilled rubber & 1.02 & $(1.02)$ & (0) \\
\hline $10 \mathrm{vol} \% \mathrm{Al}_{2} \mathrm{O}_{3}$ particles & 1.30 & 1.317 & 1.3 \\
\hline 20 vol $\% \mathrm{Al}_{2} \mathrm{O}_{3}$ particles & 1.59 & 1.614 & 1.5 \\
\hline 5 vol $\% \mathrm{Al}_{2} \mathrm{O}_{3}$ fibres $(7 \mathrm{~min})$ & 1.14 & 1.168 & 2.4 \\
\hline 5 vol $\% \mathrm{Al}_{2} \mathrm{O}_{3}$ fibres $(3 \mathrm{~min})$ & 1.15 & 1.168 & 1.5 \\
\hline $10 \mathrm{vol} \% \mathrm{Al}_{2} \mathrm{O}_{3}$ fibres $(7 \mathrm{~min}$ ) & 1.21 & 1.317 & 8.1 \\
\hline 10 vol $\% \mathrm{Al}_{2} \mathrm{O}_{3}$ fibres $(3 \mathrm{~min})$ & 1.27 & 1.317 & 3.6 \\
\hline $\mathrm{Al}_{2} \mathrm{O}_{3}$ & - & $(3.99)$ & $(0)$ \\
\hline
\end{tabular}

curve measurement (in the elastic regime) and, secondly, tensile creep testing under a fixed load.

\subsubsection{Tensile testing}

The tensile testing was carried out using a Tinius Olsen H25KS universal tester. Details were provided in the previous paper (Cui et al. 2020). All samples were about 90-100 mm long, with a gauge length of about $75 \mathrm{~mm}$. Displacements were measured via the crosshead. The nominal strain was thus equal to this displacement over the gauge length, while the nominal stress was the load divided by the original cross-sectional area. During these tests, which were carried out relatively quickly (within about $30 \mathrm{~s}$ ), the deformation was almost entirely elastic. As emphasized in the Introduction, the large strains that arise during (elastic) deformation of rubbers create substantial differences between nominal and true stresses and strains. The following should be noted concerning this. The classical rubber elasticity equation can be written:

$$
\sigma_{N}=k \operatorname{Tn}\left(\lambda-\frac{1}{\lambda^{2}}\right)=k \operatorname{Tn}\left(1+\varepsilon_{N}-\frac{1}{\left(1+\varepsilon_{N}\right)^{2}}\right)
$$

where $\sigma_{N}$ is the nominal stress, $k$ is Boltzmann's constant, $T$ is the absolute temperature, $n$ is the number of chain segments per unit volume, $\lambda$ is the extension ratio and $\varepsilon_{N}$ is the nominal strain. The relationships between true and nominal stresses and strains are

$$
\begin{aligned}
& \sigma_{T}=\sigma_{N}\left(1+\varepsilon_{N}\right) \\
& \varepsilon_{T}=\ln \left(1+\varepsilon_{N}\right), \quad \text { i.e. } \mathrm{e}^{\varepsilon_{T}}=\left(1+\varepsilon_{N}\right) \\
& \therefore \varepsilon_{N}=\mathrm{e}^{\varepsilon_{T}}-1
\end{aligned}
$$

Therefore, Eq. (1) can be rewritten in terms of true stress and true strain

$$
\begin{aligned}
\frac{\sigma_{T}}{1+\varepsilon_{N}} & =\frac{\sigma_{T}}{1+\left(\mathrm{e}^{\varepsilon_{T}}-1\right)}=k \operatorname{Tn}\left(1+\left(\mathrm{e}^{\varepsilon_{T}}-1\right)-\frac{1}{\left(1+\mathrm{e}^{\varepsilon_{T}}-1\right)^{2}}\right) \\
\therefore \sigma_{T} & =\mathrm{e}^{\varepsilon_{T}} k \operatorname{Tn}\left(\mathrm{e}^{\varepsilon_{T}}-\frac{1}{\left(\mathrm{e}^{\varepsilon_{T}}\right)^{2}}\right)=k \operatorname{Tn}\left(\mathrm{e}^{2 \varepsilon_{T}}-\frac{1}{\mathrm{e}^{\varepsilon_{T}}}\right)
\end{aligned}
$$




\subsubsection{Creep testing}

Creep tests were carried out using the customized set-up described in the previous paper (Cui et al. 2020). The system was first equilibrated thermally by switching on the heater, which was governed by one of the three thermocouples in contact with the sample. This was done with the sample under a small load - just the weight of the scale-pan. It was confirmed (Cui et al. 2020) that the time needed for thermal equilibrium was short (ca 5-10 min). Once the sample was thermally stable, the load was quickly applied to the scale pan. A short period then followed during which the system reached some kind of mechanical equilibrium, which probably involved a degree of settling and load redistribution in the gripping system and loading train, as well as some oscillation. The extension measured during this period of mechanical equilibration (typically a few tens of seconds) was not primarily arising from actual creep of the sample, so it was neglected when calculating the creep strain.

For the unfilled rubber and the two particulate composites, the loads used were $9.8 \mathrm{~N}$, 11.8 $\mathrm{N}$ and $14.7 \mathrm{~N}$, corresponding to nominal stresses of $0.17 \mathrm{MPa}, 0.21 \mathrm{MPa}$ and $0.26 \mathrm{MPa}$. For the fibrous composites, which exhibited considerably greater creep resistance, the loads were $14.7 \mathrm{~N}, 17.6 \mathrm{~N}$ and $19.6 \mathrm{~N}$ (nominal stresses of $0.26 \mathrm{MPa}, 0.31 \mathrm{MPa}$ and $0.35 \mathrm{MPa}$ ). Of course, the corresponding true stress levels at the start of the creep test depended on the sample stiffness.

\section{Mechanical testing outcomes}

\subsection{Tensile testing}

Figure 3 shows the stress-strain plots obtained at room temperature, expressed as (a) nominal and (b) true values. The former were obtained by converting load and displacement data to stresses and strains, while the latter were obtained by applying Eqs. (3) and (4) to these data. For the unfilled rubber, and for the fibre composites, these tests were taken to final rupture, but this was not done for the particulate composites, which were tested only to about $30-40 \%$ strain. This is not so important, since it can be seen (Fig. 3(b)) that they are all quite close to being linearly elastic, at least up to (true) strains of about $60-80 \%$, which covers the range of interest here. A single Young's modulus value can thus be ascribed to each of them, as shown in Fig. 3(b). As was noted previously for the unfilled rubber and for the particulate composites, the dependence of this value on temperature is small over the range concerned.

It was also noted previously (Cui et al. 2020) that the experimental (nominal) stressstrain curve for the unfilled rubber conformed well to the classical (entropy-dominated) rubber elasticity curve of Eq. (1) and that was used to obtain an estimate for $n$ of $6.5 \times$ $10^{25} \mathrm{~m}^{-3}$.

The stiffening effects produced by both particulate and fibre additions are broadly consistent with predictions from the Eshelby model, details of which are available in Clyne and Hull (2019), Taya and Arsenault (1987), Withers et al. (1989), Johannesson and Pedersen (1998). This can be seen in Fig. 4(a), which shows a comparison between measured and modeled Young's moduli for all 6 of the composite materials. The elastic constants used in the model are shown in Table 2. It can be seen that the data for the particulate composites are consistent with the presence of equiaxed particles (i.e. spheres, $s=1$ ), as expected, while those for the fibrous composites are consistent with aspect ratios of about 16 and 10 respectively for the short ( $3 \mathrm{~min}$ ) and long ( $7 \mathrm{~min}$ ) milling times, respectively. This is also broadly 

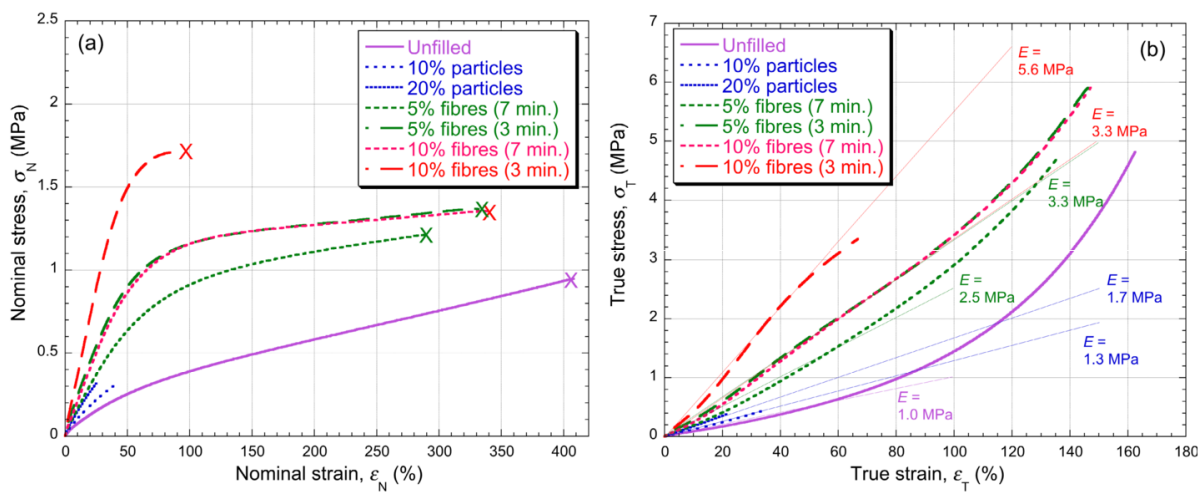

Fig. 3 Stress-strain data from tensile tests on all 7 materials at $20{ }^{\circ} \mathrm{C}$, plotted as (a) nominal and (b) true values. (Values of the effective Young's modulus are also shown)
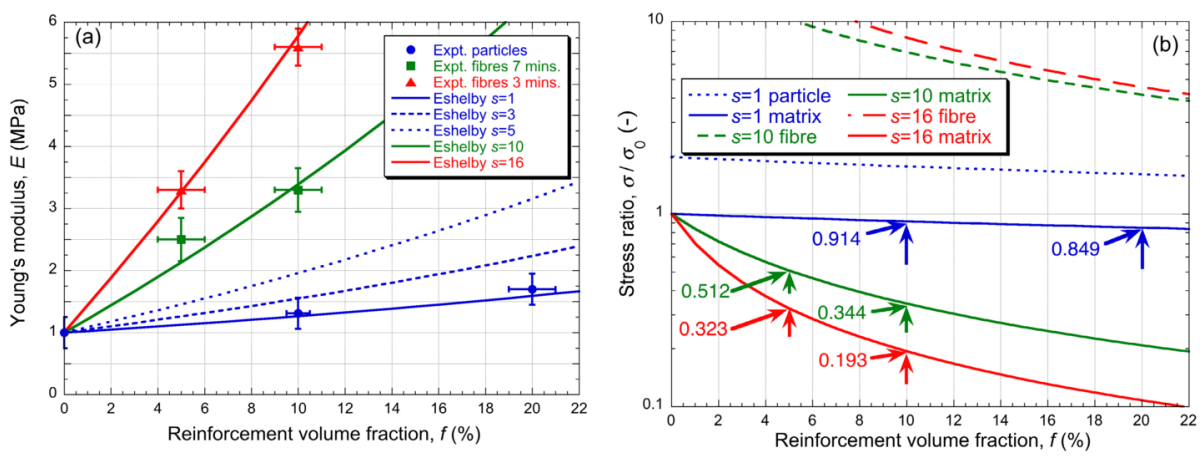

Fig. 4 Eshelby model predictions for alumina spheres and prolate ellipsoids in a rubber matrix, as a function of reinforcement volume fraction, showing (a) Young's modulus (with measured values also shown) and (b) ratio of the stress in the two constituents to an applied tensile stress

Table 2 Elastic constants used in the Eshelby modelling

\begin{tabular}{lll}
\hline Material & Young's modulus, $E(\mathrm{GPa})$ & Poisson ratio, $v(-)$ \\
\hline Rubber & 0.001 & 0.48 \\
$\mathrm{Al}_{2} \mathrm{O}_{3}$ & 300 & 0.22 \\
\hline
\end{tabular}

in line with the microstructural observations (Figs. 1 and 2), accepting that the fibre alignment is not perfect, which would tend to reduce the effective aspect ratio. These values of $s$ have thus been taken to be representative (for both volume fractions) of the reinforcement architecture in these two types of composites.

The plots in Fig. 4(b) show predicted values for the (uniform) stress in the reinforcement and the (average) stress in the matrix, as a function of the reinforcement volume fraction, for these three aspect ratios $(s=1,10$ and 16). These stresses are shown as ratios to an applied tensile stress, parallel to the axis of fibre alignment. These ratios are marked on the plot for the 6 cases of interest here. It can be seen that, as expected, stress transfer from matrix to reinforcement, at a given value of $f$, is much more marked for the fibres than 
for the particulate. The matrix is thus being relieved of stress more effectively in the fibrereinforced composites. Among other effects, this is expected to make those materials more resistant to creep than the particulate composites, for a given reinforcement content.

\subsection{Creep behaviour of matrix and composites}

\subsubsection{Use of the Miller-Norton model}

A model that captures both primary and secondary regimes of creep strain histories, with a smooth transition between them, is required in order to model the behaviour in this type of test (of relatively short duration). The formulation used here is that commonly termed the Miller-Norton law, which may be written:

$$
\varepsilon_{c r}=\frac{C \sigma^{n} t^{m+1}}{m+1}=\frac{A \sigma^{n} t^{m+1}}{m+1} \exp \left(\frac{-Q}{R T}\right)
$$

in which $\epsilon_{c r}$ is the (true) creep strain, $C$ and $A$ are both constants (units of $\mathrm{MPa}^{-n} \mathrm{~s}^{-(m+1)}$ ), $t$ is the time (s), $\sigma$ is the applied (true) stress (in MPa), $n$ is the stress exponent, $T$ is the absolute temperature, $R$ is the universal gas constant and $m$ is a dimensionless constant that controls the shape of the time dependence. This formulation is based on the assumption that the creep is thermally activated, with an activation energy of $Q \mathrm{~J}$ mole ${ }^{-1}$. Note should be made of the use of the symbol $n$ for both the number of chain segments per unit volume (Eq. (1)) and for this stress exponent. Also, $\sigma$ should be taken as the true stress (unless it has the subscript $N$ ).

The stress level used was taken to be the true value at the start of the creep (after the elastic deformation). This was obtained from the applied load by converting it to a nominal stress using the original sectional area and then applying Eq. (2), knowing the nominal elastic strain (obtained from the plots in Fig. 3(a)). The further (small) changes in true stress as the creep progressed were neglected.

\subsubsection{Creep of unreinforced rubber}

As reported in the previous publication (Cui et al. 2020), it was found that the creep behaviour of the unfilled rubber conforms well to the Miller-Norton formulation, using appropriate values for the parameters $m$ and $n$, with the value of $C$ being adjusted for the different test temperatures. The plots concerned, for the 3 different levels of applied stress, are shown in Fig. 5. Furthermore, from the values of $C$ found to give the best fit for the 3 temperatures, the activation energy, $Q$, was found (Cui et al. 2020) to be ca $7.4 \mathrm{~kJ}^{\text {mole }}{ }^{-1}$. Of course, this is only a rough estimate, but the fact that it is a relatively low value is indicative of the ratedetermining process being one of molecular reorganization, such as an untangling process, rather than involving rupture of cross-links or backbone bonds.

\subsubsection{Creep of composites}

The greater stiffness levels of the composites, compared with the unreinforced rubber, meant that the elastic strains were lower and so the true stresses (acting at the start of the creep testing) were also lower. This effect is additional to that of the creep rate being reduced in the composites by the average stress in the matrix being lower than that acting on the sample as a whole (recognizing that creep only takes place in the matrix). This was studied in the previous paper (Cui et al. 2020) for the particulate composites. Good agreement was observed 
Fig. 5 Measured and modeled creep strain histories for the unfilled rubber at (a) $20^{\circ} \mathrm{C}$, (b) $45^{\circ} \mathrm{C}$ and (c) $65^{\circ} \mathrm{C}$. The values of the initial true stress (after elastic deformation) are shown in the legend of panel (a)
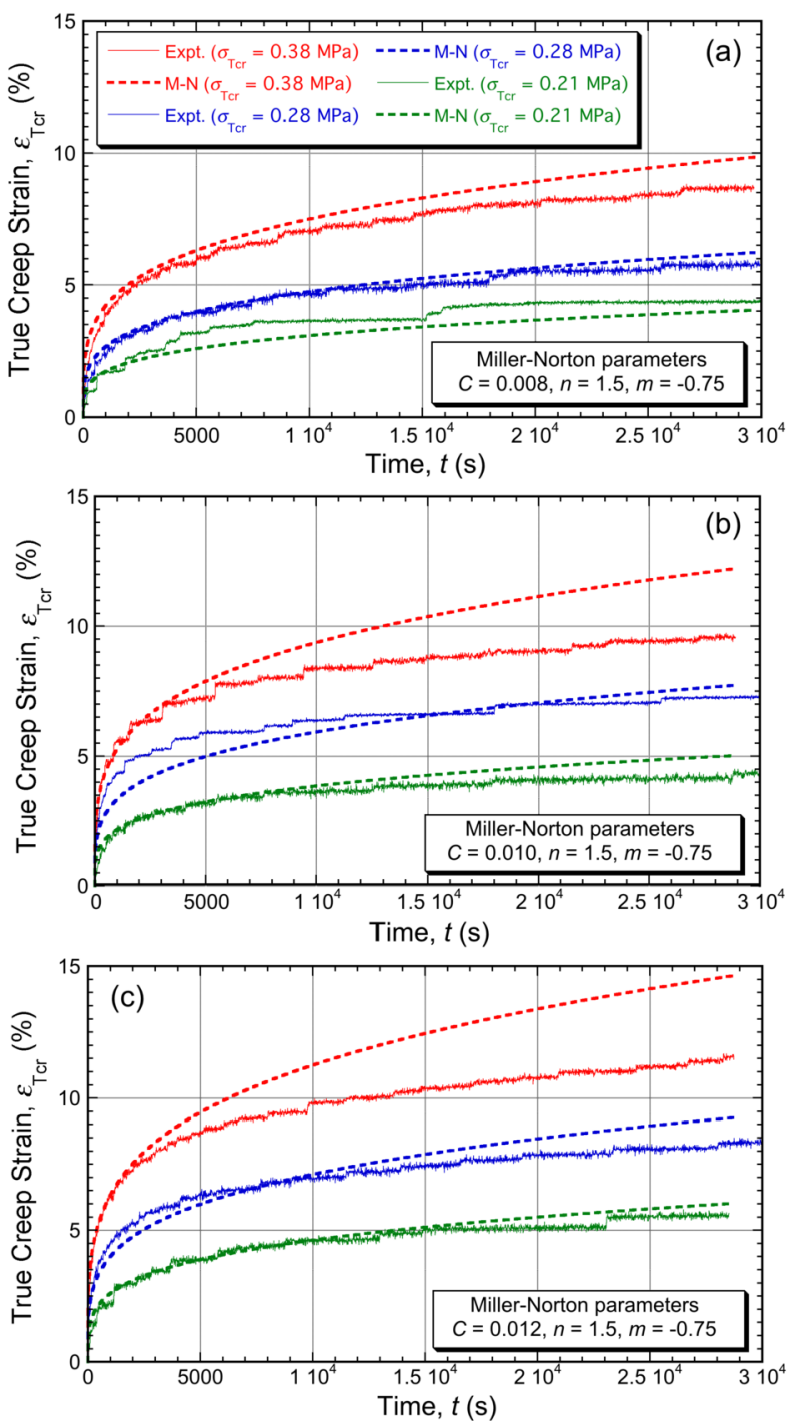

between experiment and prediction for the creep strain histories by using the (Eshelbypredicted) average matrix stress in the $\mathrm{M}-\mathrm{N}$ model, and also taking account of the reduced volume of the sample in which the creep was occurring. In fact, while those composites did exhibit noticeably better creep resistance than the unfilled rubber, the differences were not dramatic, even at the $20 \%$ addition level. This is consistent with the associated enhancement in stiffness being fairly moderate (from $1 \mathrm{MPa}$ to $1.7 \mathrm{MPa}$ - see Fig. 4(a)) and the reduction in average matrix stress also being relatively small (multiplied by a factor of about $85 \%$ see Fig. 4(b)).

The focus of the current paper is on the behaviour of the fibre-reinforced composites. In these cases, even at the $10 \%$ addition level, the stiffness enhancement is substantial (from $1 \mathrm{MPa}$ to about 5.6 MPa for the higher aspect ratio fibres - see Fig. 4(a)) and the corresponding reduction in average matrix stress is also pronounced (to about $19 \%$ for that composite - 
Fig. 6 Measured and modeled creep strain histories for the $5 \%$ fibrous composite ( 7 mins. milling time) at (a) $20^{\circ} \mathrm{C}$ and (b) $65^{\circ} \mathrm{C}$. Initial true stress values are shown in the legend of panel (a), as are the average values in the matrix (used in the $\mathrm{M}-\mathrm{N}$ model)
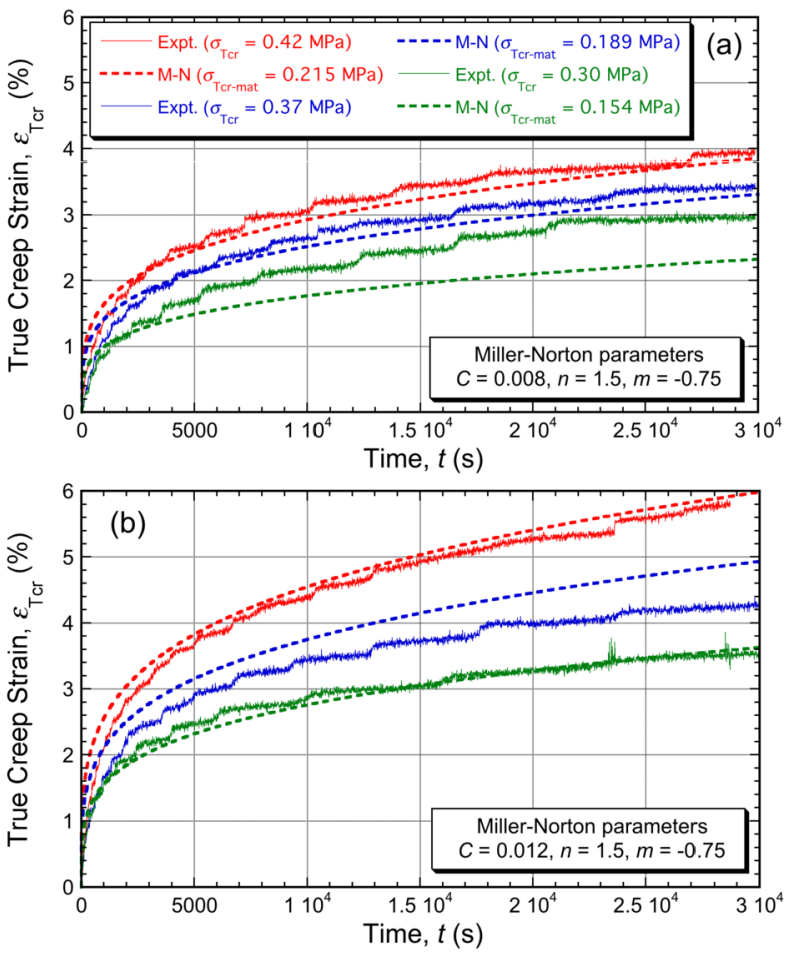

see Fig. 4(b)). The reductions in creep rate are thus expected to be appreciably greater with the fibrous reinforcement. This is quantitatively explored here, using the same type of analysis - i.e. the Miller-Norton formulation, using the same parameter values as those found appropriate for the unfilled rubber, with the matrix stress level being that obtained from the Eshelby model.

For example, Fig. 6 shows (for temperatures of $20^{\circ} \mathrm{C}$ and $65^{\circ} \mathrm{C}$ ) experimental and predicted creep curves for the 5\% composite containing fibres that had been milled for $7 \mathrm{~min}$ (such that the average fibre aspect ratio in the composites was about 10 - see Fig. 4(a)). For the applied nominal stresses of $0.26 \mathrm{MPa}, 0.31 \mathrm{MPa}$ and $0.35 \mathrm{MPa}$, the nominal strains at the start of the creep tests were about $16.8 \%, 20.5 \%$ and $23.5 \%$ (true strains of $15.5 \%, 18.6 \%$ and $21.1 \%$ ) and the corresponding true stresses were $0.30 \mathrm{MPa}, 0.37 \mathrm{MPa}$ and $0.42 \mathrm{MPa}$. Using the "stress reduction factor" of 0.512 for this composite (Fig. 4(b)), these give average matrix stresses for use in the M-N equation of $0.154 \mathrm{MPa}, 0.189 \mathrm{MPa}$ and $0.215 \mathrm{MPa}$. While the agreement is naturally not perfect, it can be seen that the experimental creep data are broadly consistent with this modelling approach, capturing the effects of both applied stress and temperature. Corresponding plots for the other three fibre-reinforced composites are shown in Figs. 7, 8 and 9. These predicted curves were obtained using the multipliers shown in Fig. 4(b) to obtain the average matrix stress levels. The plots were also multiplied by factors of 0.95 or 0.90 , to take account of the effect of the creep taking place only in those volume fractions of the samples. It can be seen that the level of agreement is again good in all cases.

It is certainly striking that creep is much more strongly inhibited in the fibrous composites, compared with the particle-reinforced materials. For example, with an applied nominal stress of $0.26 \mathrm{MPa}$ at $20^{\circ} \mathrm{C}$ (a condition used for all materials), the total creep strain after a 
Fig. 7 Measured and modeled creep strain histories for the $5 \%$ fibrous composite (3-min milling) at (a) $20^{\circ} \mathrm{C}$ and (b) $65^{\circ} \mathrm{C}$. Initial true stress values are shown in the legend of panel (a), as are the average values in the matrix (used in the $\mathrm{M}-\mathrm{N}$ model)

Fig. 8 Measured and modeled creep strain histories for the $10 \%$ fibrous composite (7-min milling) at (a) $20^{\circ} \mathrm{C}$ and (b) $65^{\circ} \mathrm{C}$. Initial true stress values are shown in the legend of panel (a), as are the average values in the matrix (used in the M-N model)
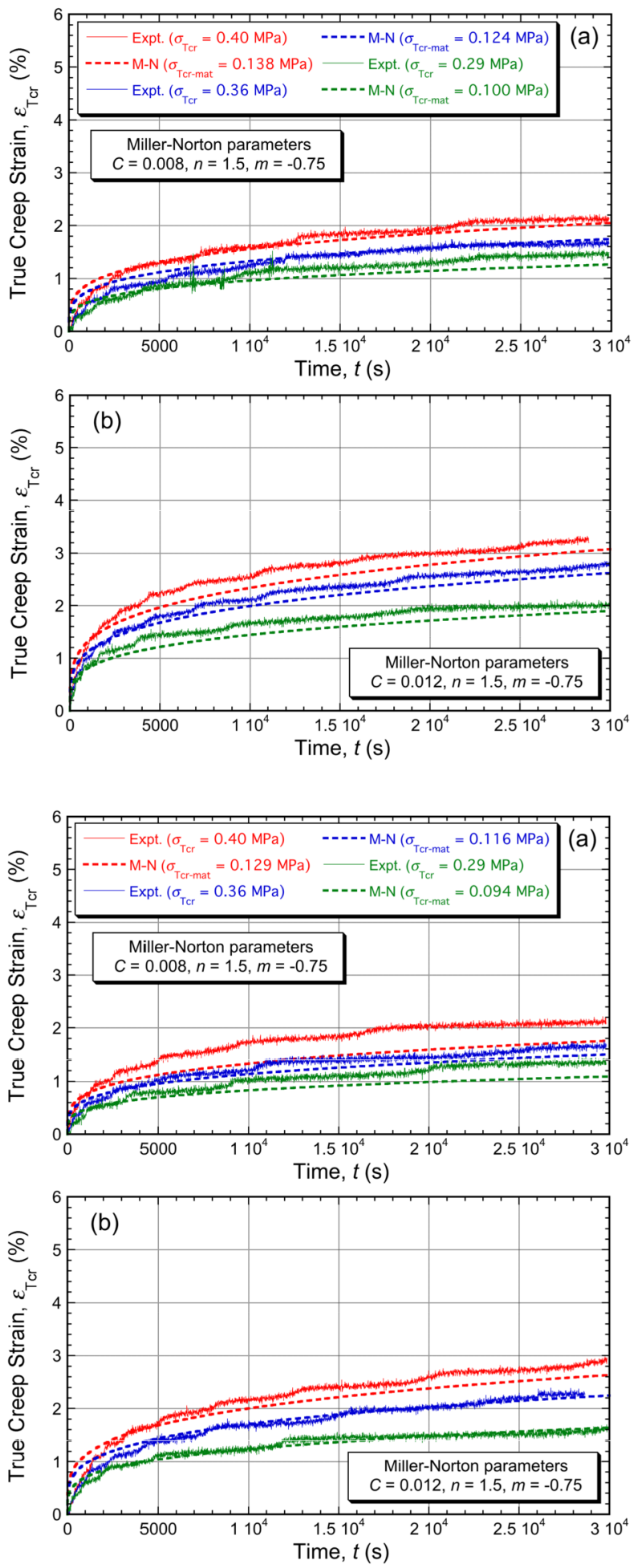
Fig. 9 Measured and modeled creep strain histories for the $10 \%$ fibrous composite (3-min milling) at (a) $20^{\circ} \mathrm{C}$ and (b) $65^{\circ} \mathrm{C}$. Initial true stress values are shown in the legend of panel (a), as are the average values in the matrix (used in the $\mathrm{M}-\mathrm{N}$ model)
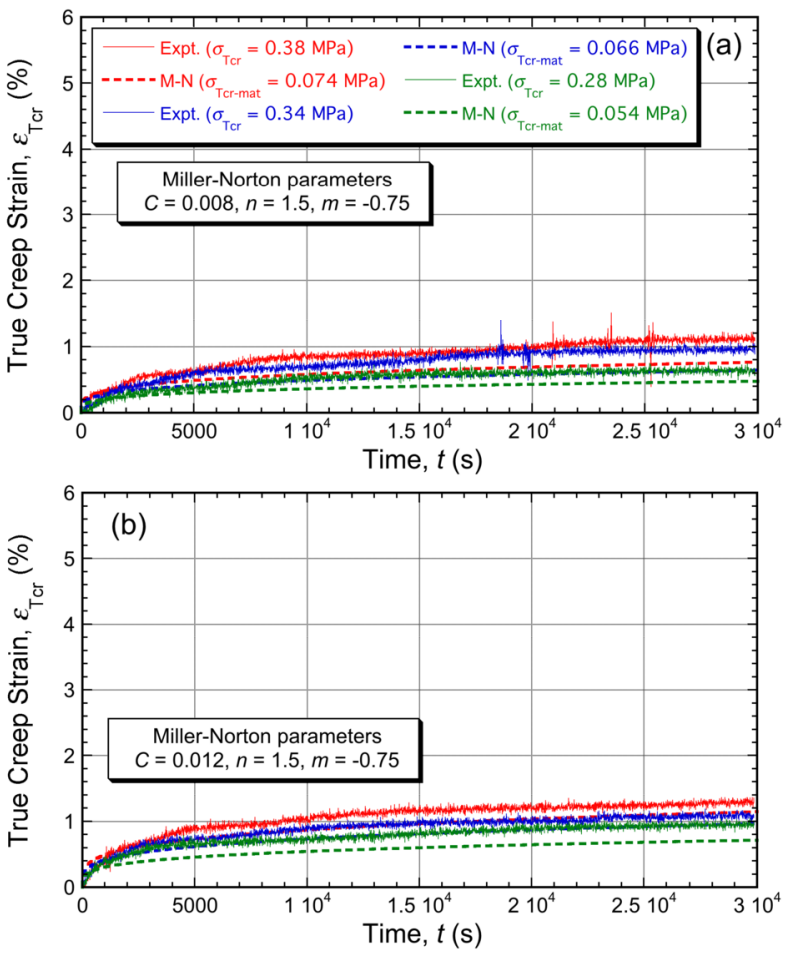

period of $3 \times 10^{4} \mathrm{~s}$ (about $8 \mathrm{~h}$ ) is about $8.5 \%$ for the unfilled rubber, $6 \%$ for the $10 \%$ particulate composite and $4 \%$ for the $20 \%$ particulate composite. For the fibrous composites, on the other hand, the figures are about $3 \%, 2 \%, 1.4 \%$ and $0.6 \%$ (respectively for two 5\% contents and the two $10 \%$ contents). Put another way, at the $10 \%$ addition level, the presence of the particulate effects a relatively small reduction (of about 30\%) in the creep strain of the rubber, whereas fibres can cut it down by over $90 \%$.

\section{Conclusions}

An investigation has been made into the effect of introducing particulate or short fibre reinforcement on the creep behaviour of a rubber. The following conclusions can be drawn from this work:

(a) Samples of polyurethane rubber, with and without alumina reinforcement (as either particles or short fibres, aligned in the loading direction, at levels of 5, 10 and $20 \mathrm{vol} \%$ ), have been subjected to both tensile (stress-strain) testing (in the elastic regime) and tensile creep (constant load) testing, at three different temperatures (up to $65^{\circ} \mathrm{C}$ ).

(b) Plotted as true stress-strain values, all seven of the materials exhibited approximately linear elastic behaviour over the strain range of interest (up to about $80 \%$ ). The effective values of the Young's moduli for the composites were found to be consistent with predictions from the Eshelby (equivalent homogeneous inclusion) model, with the particles taken to be spheres and the fibres to be prolate ellipsoids with the same aspect ratios. 
(c) The creep strain curves, measured over a period of about $8 \mathrm{~h}$, were found to fit well in all cases with predictions obtained using the Miller-Norton equation, including the dependence on temperature and applied stress (taken to be the true stress acting at the start of the creep period). The presence of the reinforcement thus reduces the creep rate of the unreinforced matrix via both the increase in stiffness (reducing the true stress acting on the sample) and the reduction in average matrix stress due to stress transfer.

(d) The stress transfer effect has been simulated using the Eshelby model, with the resultant average matrix stress used in the Miller-Norton equation (and account also taken of the reduction in the volume fraction of the sample in which the creep is occurring). The creep curves predicted in this way were in good agreement with experiment for all six of the composite materials, capturing the effect of reinforcement aspect ratio, as well as volume fraction.

(e) A striking outcome of both the experiments and the simulations is that (short) fibres provide much greater increase in creep resistance than particles (at a given reinforcement level). This is the case for both fibre aspect ratios used, but even the lower value $(s \sim 10)$ has a strong effect. The production of composite material containing high $(>\sim 10 \%)$ fibre contents may be problematic, but the improvement in creep resistance is marked even for the levels studied here (5\% and 10\%). Furthermore, while this work has covered only composites with a degree of fibre alignment (along the loading direction), it is likely that isotropic material containing (low levels of) short fibres of this type will show strong improvements in creep resistance under multi-axial loading.

Acknowledgements This work has been supported by EPSRC, via an industrial CASE award (for YC) with AWE (EP/R511870/1).

(C) British Crown Copyright 2020/AWE.

Data Availability Original data will be made available on request.

Open Access This article is licensed under a Creative Commons Attribution 4.0 International License, which permits use, sharing, adaptation, distribution and reproduction in any medium or format, as long as you give appropriate credit to the original author(s) and the source, provide a link to the Creative Commons licence, and indicate if changes were made. The images or other third party material in this article are included in the article's Creative Commons licence, unless indicated otherwise in a credit line to the material. If material is not included in the article's Creative Commons licence and your intended use is not permitted by statutory regulation or exceeds the permitted use, you will need to obtain permission directly from the copyright holder. To view a copy of this licence, visit http://creativecommons.org/licenses/by/4.0/.

\section{References}

Aboudi, J.: Micromechanics-based thermoviscoelastic constitutive equations for rubber-like matrix composites at finite strains. Int. J. Solids Struct. 41(20), 5611-5629 (2004)

Banerjee, S.S., Bhowmick, A.K.: High temperature thermoplastic elastomers from rubber plastic blends: a state-of-the-art review. Rubber Chem. Technol. 90(1), 1-36 (2017)

Bocchieri, R.T., Schapery, R.A.: Time-dependent deformation and damage growth in a rubber-toughened fiber composite. Mech. Time-Depend. Mater. 8(2), 137-167 (2004)

Chen, C.H., Cheng, C.H.: Micromechanical modeling of creep behavior in particle-reinforced silicone-rubber composites. J. Appl. Mech. 64(4), 781-786 (1997)

Clyne, T.W., Hull, D.: An Introduction to Composite Materials, 3rd edn. Cambridge University Press, Cambridge (2019)

Clyne, T.W., Mason, J.F.: The squeeze infiltration process for fabrication of metal matrix composites. Metall. Trans. 18A, 1519-1530 (1987)

Clyne, T.W., Bader, M.G., Cappleman, G.R., Hubert, P.A.: The use of a $\Delta$-alumina fibre for metal-matrix composites. J. Mater. Sci. 20(1), 85-96 (1985) 
Cui, Y., Campbell, J.E., Burley, M., Patel, M., Hunt, K., Clyne, T.W.: Effects of temperature and filler content on the creep behaviour of a polyurethane rubber. Mech. Mater. 148, 103461 (2020)

Das, A.A., Clegg, A.J., Zantout, B.: Enhancement in the properties of a squeeze-cast aluminium magnesium alloy containing delta-alumina fibre. In: Cast Reinforced Metal Composites, pp. 217-224. ASM, Chicago (1988)

Daver, F., Kajtaz, M., Brandt, M., Shanks, R.A.: Creep and recovery behaviour of polyolefin-rubber nanocomposites developed for additive manufacturing. Polymers 8(12), 437 (2016)

Derham, C.J.: Creep and stress relaxation of rubbers - effects of stress history and temperature changes. J. Mater. Sci. 8(7), 1023-1029 (1973)

Derham, C.J., Thomas, A.G.: Creep of rubber under repeated stressing. Rubber Chem. Technol. 50(2), 397-402 (1977)

Friend, C.M.: The effect of matrix properties on reinforcement in short alumina fibre-aluminium metal matrix composites. J. Mater. Sci. 22, 3005-3010 (1987)

Johannesson, B., Pedersen, O.B.: Analytical determination of the average Eshelby tensor for transversely isotropic fiber orientation distributions. Acta Mater. 46(9), 3165-3173 (1998)

Lee, B.L., Liu, D.S.: Cumulative damage of fiber-reinforced elastomer composites under fatigue loading. J. Compos. Mater. 28(13), 1261-1286 (1994)

Lee, B.S., Rivin, E.I.: Finite element analysis of load-deflection and creep characteristics of compressed rubber components for vibration control devices. J. Mech. Des. 118(3), 328-336 (1996)

Luo, R.K.: Creep modelling and unloading evaluation of the rubber suspensions of rail vehicles. Proc. Inst. Mech. Eng., F J. Rail Rapid Transit 230(4), 1077-1087 (2016)

Ngo, A.T., Valdes, J.R.: Creep of sand-rubber mixtures. J. Mater. Civ. Eng. 19(12), 1101-1105 (2007)

Oman, S., Nagode, M.: Observation of the relation between uniaxial creep and stress relaxation of filled rubber. Mater. Des. 60, 451-457 (2014)

Plazek, D.J.: Effect of crosslink density on creep behavior of natural rubber vulcanates. J. Polym. Sci. Part A-2, Polym. Phys. 4(5PA2), 745 (1966)

Ramachandran, P., Dutta, J., Chatterjee, T., Nando, G.B., Naskar, K.: Investigation of different cross-linking methods of EOC: PDMS thermoplastic elastomers for cable insulation application with special reference to thermal, rheological, creep and electrical properties. Rubber Chem. Technol. 90(4), 585-610 (2017)

Sagar, G., Zheng, D., Suwannachit, A., Brinkmeier, M., Fietz, K., Hahn, C.: On the development of creep laws for rubber in the parallel rheological framework. Tire Sci. Technol. 47(1), 2-30 (2019)

Taya, M., Arsenault, R.J.: A comparison between a shear lag type model and an Eshelby type model in predicting the mechanical properties of a short fibre composite. Scr. Metall. 21, 349-354 (1987)

Withers, P.J., Stobbs, W.M., Pedersen, O.B.: The application of the Eshelby method of internal stress determination for short fibre metal matrix composites. Acta Metall. 37, 3061-3084 (1989)

Publisher's Note Springer Nature remains neutral with regard to jurisdictional claims in published maps and institutional affiliations. 